

\title{
Experimental Determination of the Miscibility Gap in High Purity Iron-Chromium Alloys
}

\author{
V. Nika, J. Bigot
}

\section{To cite this version:}

V. Nika, J. Bigot. Experimental Determination of the Miscibility Gap in High Purity Iron-Chromium Alloys. Journal de Physique IV Proceedings, 1995, 05 (C7), pp.C7-265-C7-270. 10.1051/jp4:1995731 . jpa-00254025

\section{HAL Id: jpa-00254025 https://hal.science/jpa-00254025}

Submitted on 1 Jan 1995

HAL is a multi-disciplinary open access archive for the deposit and dissemination of scientific research documents, whether they are published or not. The documents may come from teaching and research institutions in France or abroad, or from public or private research centers.
L'archive ouverte pluridisciplinaire HAL, est destinée au dépôt et à la diffusion de documents scientifiques de niveau recherche, publiés ou non, émanant des établissements d'enseignement et de recherche français ou étrangers, des laboratoires publics ou privés. 


\title{
Experimental Determination of the Miscibility Gap in High Purity Iron-Chromium Alloys
}

\author{
V. Nika and J. Bigot
}

CNRS/CECM, 15 rue G. Urbain, 94407 Vitry, France

\begin{abstract}
We have experimentally established the miscibility gap in the iron - chromium system by studying ageing of alloys prepared from high purity materials. Samples were obtained by levitation melting. Alloys with less than $50 \%$ of chromium were cold worked, otherwise sheets were cut from the ingot. Evolution of samples with different compositions, from 17 to $90 \%$, initially quenched from $900^{\circ} \mathrm{C}$ was followed during isothermal annealing at different temperatures between 475 and $650^{\circ} \mathrm{C}$. Electrical ratio $\mathrm{R}$ $\mathrm{He}^{=} \rho_{4,2 \mathrm{~K}} / \rho_{273} \mathrm{~K}$ and Vickers hardness plots show that the kinetics are at a maximum for $35 \%$ chromium alloys aged at $500^{\circ} \mathrm{C}$. For samples with a content lower than $66 \%$ ageing produced an increase of the electrical ratio $\mathrm{R}_{\mathrm{He}}$ and hardness. At $66 \%$ there is an instability in $\mathrm{R}_{\mathrm{He}}$, whereas for $80 \%$, it decreases.

The limit of the miscibility gap is considered to be obtained when properties are unchanged by annealing. According to our results, the limits of the unmixing zone are between 15 and $17,5 \%$ on the iron side and 75 and $80 \%$ on the chromium side. The shape is asymmetric near $550^{\circ} \mathrm{C}$ for $20 \%$ chromium and near $600^{\circ} \mathrm{C}$ for $80 \%$ alloys. Differential thermal analysis show that the evolution of the $80 \% \mathrm{Fe}-\mathrm{Cr}$ alloy is complex.
\end{abstract}

\section{Introduction}

Ferritic steels are iron-based alloys with a 12 to $20 \%$ chromium content. They make up a major group of stainless steels which were put to limited use for many years due to their low impact strength. Improved material purity and production conditions have led to major developments in this class of alloys. However, chromium-rich ferritic steels are prone to various types of embrittlement. The first type, observed when ageing the alloy between 400 and $850^{\circ} \mathrm{C}$, is well known and corresponds to the appearance of $\sigma$ phase . (1). The second, known as "embrittlement at $475^{\circ} \mathrm{C}^{\prime \prime}$ is still under study, and seems to be related to the presence of a miscibility gap and to spinodal decomposition of the solid solution (2)(3). The first curve for this miscibility gap was proposed by Williams and Paxton in 1957 (2) and later modified (4). The second curve was symmetrical about the $50 \%$ chromium composition. Both Kubacheswski (5) and Rao (6) have calculated an asymmetrical gap with a maximum at about $600^{\circ} \mathrm{C}$ and $60 \%$ chromium. Nishizawa (7), taking account of the magnetic phenomena, has calculated a curve with an anomaly near $25 \%$. The decomposition of the solid solution has been studied by Mössbauer (8), by small angle neutron scattering $(9)(10)$ and by the atomic probe method (11).

In this work, we aimed to determine experimentally the form of this miscibility gap using high-purity alloys, electrical resistivity measurements at low temperature, hardness measurements and differential thermal analysis (12). 

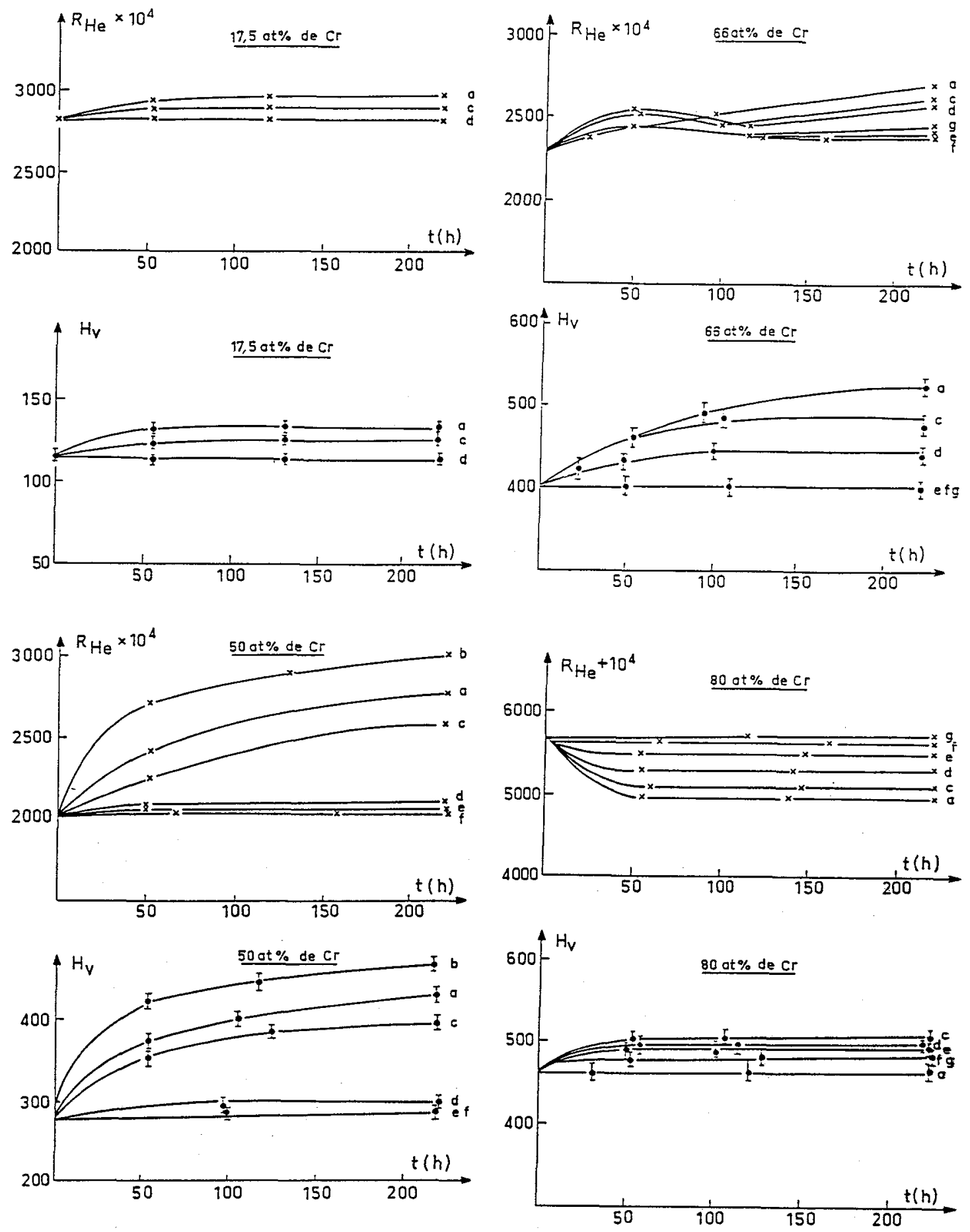

Figure 1 - Variations of the electrical ratio $\mathrm{R}_{\mathrm{He}}$ and of Vickers hardness during isothermal annealing.

$$
a=475, b=500, c=550, d=575, e=595, f=, g=650^{\circ} \mathrm{C} \text {. }
$$




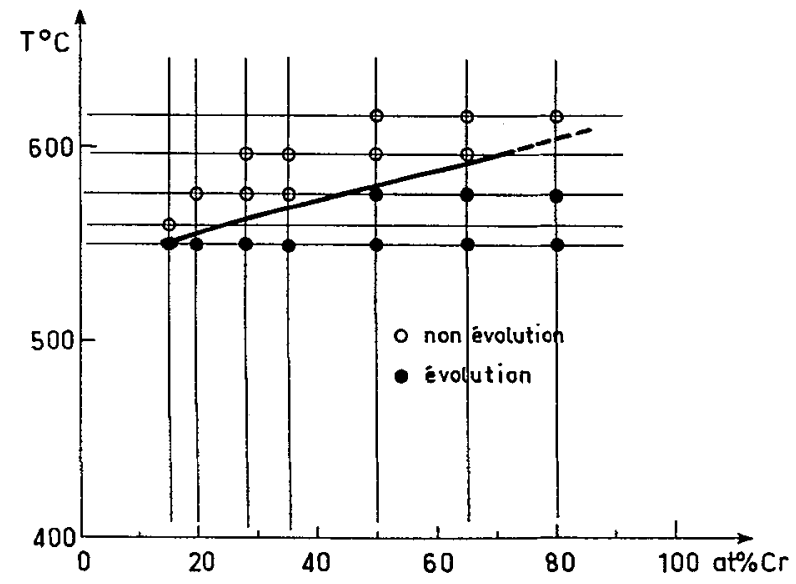

Figure 2 - Miscibility gap in the iron -chromium system obtained by electrical and hardness measurements.
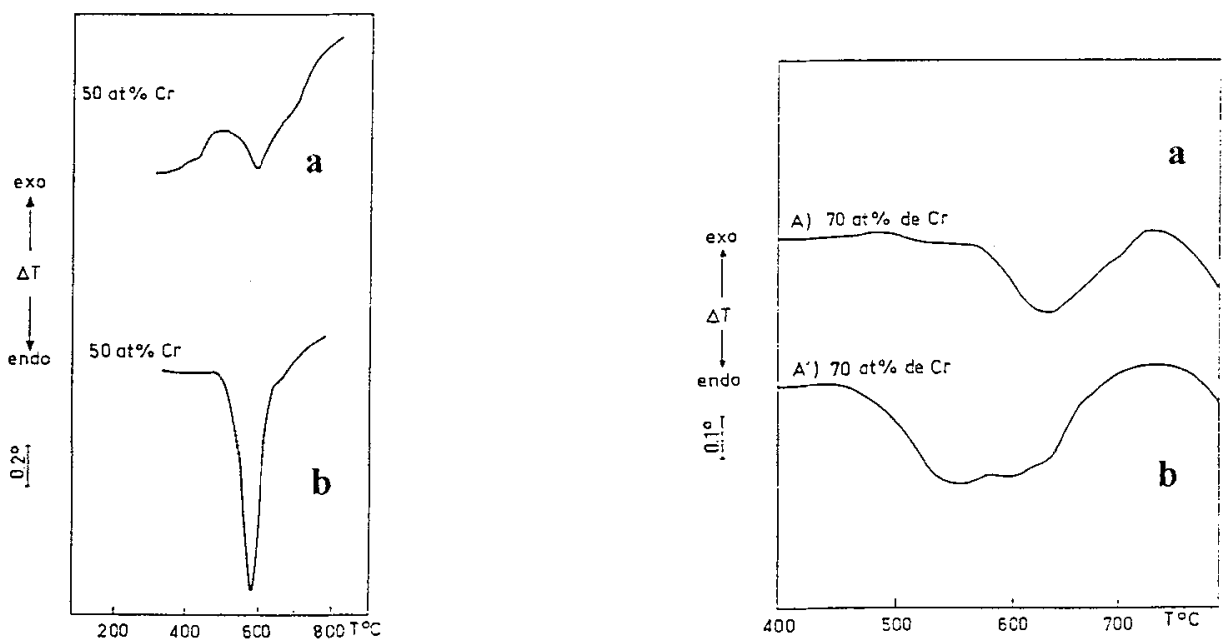

Figure 3 - Differential thermal analysis curves of $\mathrm{Fe}-\mathrm{Cr}$ alloys:

$\mathrm{Fe}-\mathrm{Cr} 50 \%$ - a / as quenched. $-\mathrm{b} /$ annealed at $475^{\circ} \mathrm{C}$.

Fe-Cr $70 \%$ - a / as quenched. - b/annealed at $700^{\circ} \mathrm{C}$ 


\section{Materials.}

The iron-chromium alloys with a composition between 15 and $90 \%$ were prepared by levitation melting under a helium atmosphere controlled by gas-phase chromatography. The initial metals used were high-purity metals, prepared at the CECM by zone melting and heat treatment. The main impurities were $C=7, N=10, O=13, R R R=500$ for iron, and $C=7$, $\mathrm{N}=0, \mathrm{O}=3, \mathrm{RRR} 250$ for chromium (13). Alloys with a chromium content less than $50 \%$ were $80 \%$ cold-rolled while for higher contents alloy plates were cut from ingots. The samples were then annealed for two hours at $900^{\circ} \mathrm{C}$ under a vacuum of $10^{-6}$ torr. Two quenching rates were tested, one by removing the samples from the oven and allowing them to cool in air, the other by quenching the samples in a Ga-In-Sn alloy at $0^{\circ} \mathrm{C}$. The second mode induces the forming of cracks for alloys whose chromium content exceeds $40 \%$ and a small hardness difference between samples, but the ageing kinetics, remain unchanged.

\section{Experimental}

The experimental methods used were electrical resistivity at low temperature and Vickers micro-hardness. Electrical resistivity values were measured at $4.2 \mathrm{~K}$ and $273 \mathrm{~K}$ and we used the ratio $\mathrm{RHe}_{\mathrm{He}}=\rho 4.2 \mathrm{~K} / \rho 293 \mathrm{~K}$. Vickers hardness measurements were carried out using a "Leitz" micro hardness tester "Durimet" with a load of $300 \mathrm{~g}$ and ten indentations per measurement. We followed up the variations of these properties during isothermal treatments made at increasing temperatures followed by air quenching. We considered that the miscibility gap limit for a given composition corresponds to the temperature above which the properties under study remain constant through isothermal annealing. In addition, differential thermal analysis tests were carried out using a "Setaram M" microanalyser with a heating rate of $5^{\circ} \mathrm{C} / \mathrm{m}$ on quenched or aged samples.

\section{Results}

The hardness variations of the quenched alloy samples, as a function of their chromium content, are identical with those obtained by Stones (14). In particular we observed the same anomaly at about $80 \%$ chromium. The $\mathrm{R}_{\mathrm{He}}$ ratio values are also in accordance with Arajs's (15). The highest hardness values correspond to the $80 \%$ alloy which, according to Fisher (16) corresponds to the composition of one of the ultimate phases of the solid solution decomposition.

We followed the evolution of the initially quenched alloys from $900^{\circ} \mathrm{C}$ through isothermal treatments at various temperatures between 475 and $650^{\circ} \mathrm{C}$. Preliminary studies indicated that 400 hours of annealing allowed relatively constant hardness to be achieved, while the resistivity ratio kept changing.

The results obtained are shown in Figure 1. For alloys with a chromium content of up to $60 \%$, the isothermal annealing results in an increase in hardness and resistivity ratio. There is no incubation time. As soon as the chromium content reaches $17.5 \%$, the alloys start evolving and keep evolving up to $550^{\circ} \mathrm{C}$. The observed variations are small and stabilise after about 50 hours. As regards the $28.5 \%$ alloy, we observed a rapid evolution for the few hours, but resistivity kept increasing beyond 2000 hours. The most significant variations were obtained with the $35 \%$ alloy.

The curves are very similar for chromium contents up to $60 \%$. As regards the $66 \%$ alloy, the $\mathrm{R}_{\mathrm{He}}$ ratio increased through the first 50 hours of aging, then we observed a decrease followed by another increase. Hardness increased in the same manner as for the other alloys. These phenomena were no longer observed as soon as the temperature exceeded $575^{\circ} \mathrm{C}$. 
For $80 \%$ chromium content, $\mathrm{R}_{\mathrm{He}}$ decreased during the first 50 hours of treatment, then stabilised. Hardness increased little during the few hours. The higher chromium content alloys no longer evolve through the various treatments.

From these results, a curve can be plotted which defines the miscibility gap separating the domain where the solid solution evolves during the thermal treatments, from the domain where it is stable.( Figure. 2) The resistivity and hardness variations are observed for alloys whose chromium content is between 17.5 and $80 \%$. In this domain, the instability limit temperature increases regularly from $550^{\circ} \mathrm{C}$ to $615^{\circ} \mathrm{C}$. For alloys whose chromium content exceeds $70 \%$, however, the phenomena appear more complex and may no longer correspond strictly to spinodal-type transformation as indicated by the results obtained by differential thermal analysis.

Through this technique, and for alloys with less than $50 \%$ chromium, an exothermic peak appears when heating, which corresponds to the decomposition of the solid solution, and du e to the positive enthalpy of dissolution of the iron-chromium alloys. As the temperature increases, when passing the miscibility limit, the composition fluctuations disappear, which causes an endothermic peak. The Curie temperatures of the alloys are shown on the curves. For the sample subjected to ageing at $475^{\circ} \mathrm{C}$, the amplitude of the second peak increases as a function of time (17). The results obtained on samples of various compositions, aged for 120 hours at $475^{\circ} \mathrm{C}$, show that the aera under the peaks corresponding to the redissolution of the composition fluctuations is maximum for the $50 \%$ alloy. The results allow a curve of the miscibility gap to be plotted less precise than the previous curve due to the position of the Curie point, but is very close still. As regards alloys with a higher chromium content, such as alloys with 70,80 and $83 \%$ chromium, two additional peaks appear at higher temperature, the first exothermic, the second endothermic. All peaks have a low amplitude, and for 83 and $86 \%$ alloys, the first two peaks are no longer detected. We attempted to increase the amplitude of the endothermic peaks by age-hardening at 475,600 and $700^{\circ} \mathrm{C}$. Annealing at $475^{\circ} \mathrm{C}$ results in an amplification of the endothermic peak of the concentration fluctuation dissolution for the $70 \%$ alloy, not for the other two. (Figure 3). This would indicate that spinodal transformation no longer occurs beyond $70 \%$ chromium. A 50 -hour ageing period at 650 or $700^{\circ} \mathrm{C}$ seems to increase the amplitude of the second endothermic peak, which may be due to the occurrence of a second evolution mode of the solid solution.

\section{Conclusions}

The results obtained indicate that the miscibility gap of iron-chromium extends over the 17.5 to $70 \%$ chromium domain. This gap is not symmetrical and the limit of the domain appears at temperatures increasing regularly from 550 to $610^{\circ} \mathrm{C}$ as the chromium content increases. These temperatures are higher than those published by YE Vintaykin (10). As regards the $45 \%$ alloy, the miscibility limit is in accordance with that determined by $\mathrm{P}$. Camus by atomic probe (11). No anomaly near $27 \%$, as suggested by $T$. Nishisawa (7), was found

The concentration domain around $80 \%$ chromium is a complex zone where several phenomena occur. Thermal analysis indicates that ageing at $475^{\circ}$ of a $70 \%$ alloy allows the transformation to be amplified. For lower contents, this transformation is identified as spinodal. This effect is no longer observed for an $80 \%$ alloy. For this composition, annealing results in a decrease of the resistivity ratio associated with a small hardness increase. Ageing- at 600 and $700^{\circ} \mathrm{C}$ amplifies the endothermic component of the second phenomenon detected by thermal analysis. It should be noted that in this concentration domain, the magnetic behaviour of these alloys is not fully understood, as iron is 
ferromagnetic and chromium anti ferromagnetic, with a spin glass behaviour of the alloys at low temperature (18)

\section{References}

(1) Pomey G. and Bastien P., Rev. Métallurgie 53 (1956) p. 149.

(2) Williams R.O.and Paxton.H.W., J. of Iron and Steel Inst.186 (1957) p. 367.

(3) Cahn J.W., Acta Met. 10 ( 1962) p. 907.

(4) Williams. R.O., Trans. Met. Soc. AIME 212 (1958) p.497.

(5) Kubaschewski O and Shart.T.G., Inst. Metal.93(1965) p. 329.

(6) Rao M.V.and Tiller. W.A., Scripta Met.6,(1972) p. 417.

(7)Nishizawa T Hasebe M and Ko M., Acta Met.27 (1979) p. 817.

(8) Chandra D. and Schwartz L.M., Metall. Trans. 2 (1971) p. 511.

(9) Vintaykin YE. Dimitriyev V.N.and Kolonstov.V.Y., Fiz. Metal. Metalloved 29 (1970) p1257.

(10) Bley.F., Acta Metall.Mater.40(7). (1992) p1505.

(11) Camus.P.P., J de Physique 48 supp 11, (1987) p 331.

(12) Nika. V., Thèse Paris (1982)

(13) Chaudron. G., Monographie sur les Métaux de Hautes Pureté, Masson Editeur (1972).

(14) Stones. H.E.N., J.of Mat Science 14(1979) p 2787.

(15) Arajs S. and Dunmyre. G.R., J. of applied physics 37 (1966) p. 1017.

(16) Fisher R.M. Dulis E.T.and Carrol. K.G., Trans. AIME 197 (1953) p. 690.

(17) Vilar RM and Cizeron. G., Ann. Chim. Paris 7 (1982) p. 25.

(18) Babic B. Kajzar F.and Parette. G., J.Phys.Chem. Solid 41 (1980) p.1303. 